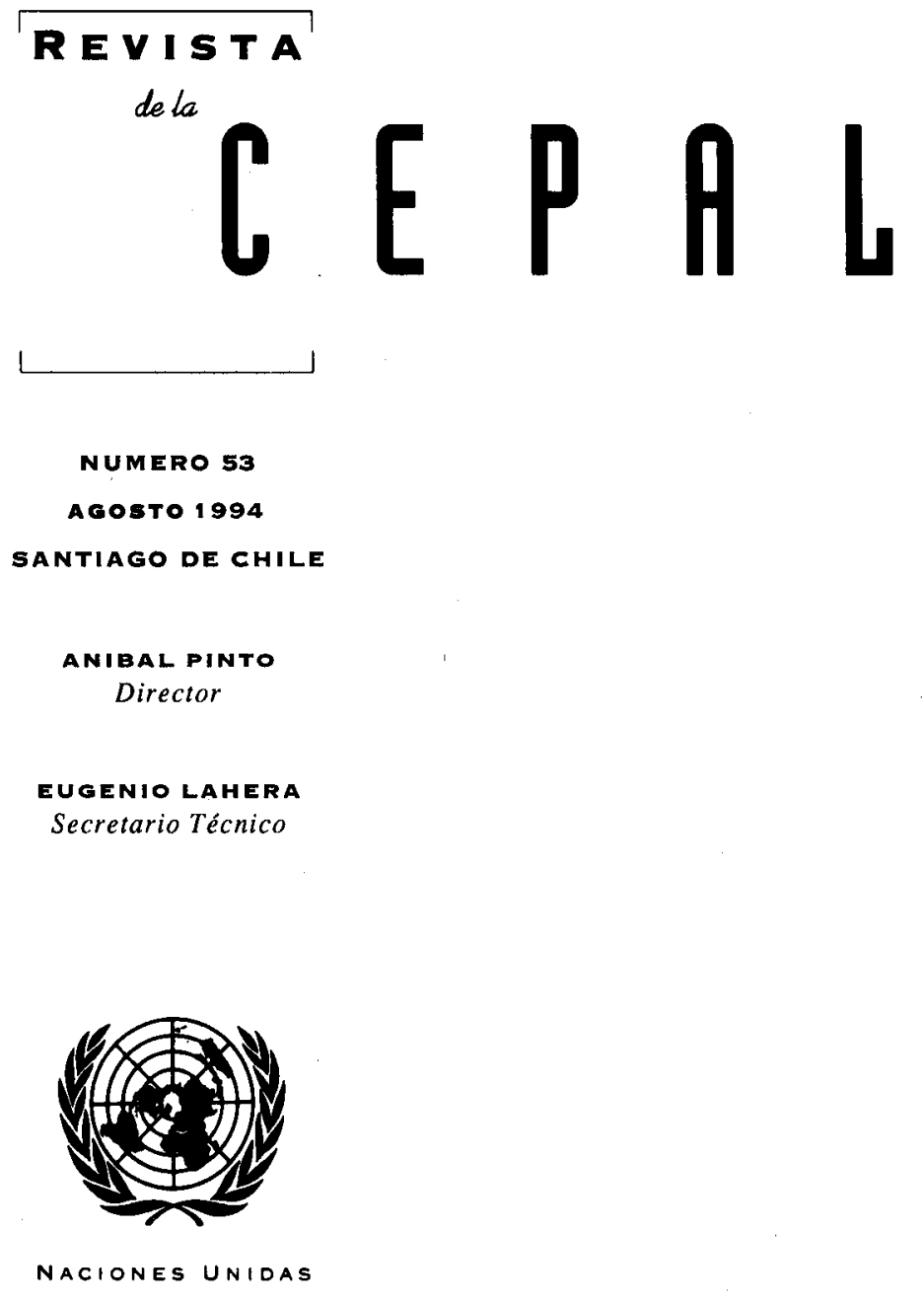


América Latina y el Caribe frente a la economía mundial

Gert Rosenthal

Afluencia de capitales externos y políticas macroeconómicas

Andras Uthoff y Daniel Titelman

Represión fínanciera y patrón de financiamlento latínoamericano

31

Marcos Antonio Macedo Cintra

Políticas de competitividad

49

Wilson Peres

Política industrial y fomento de la competitividad

Osvaldo Rosales

El regionalismo abierto y la integración económica

Juan A. Fuentes $K$.

Transformaciones del trabajo femenino urbano

91

Irma Arriagada

La gestión del agua y las cuencas en América Latina

Axel Dourojeanni

Políticas públicas y competitividad de las exportaciones

agrícolas

Milton von Hesse

Agroindustria y transformación productiva de la pequeña agricultura

Alejandro Schejtman

Grupos privados nacionales en México, 1988-1993

Celso Garrido

Evolución y perspectivas de la reforma y la apertura en China 


\section{Transformaciones del trabajo femenino urbano}

\section{Irma Arriagada}

Oficial de Asuntos Sociales de la División de Desarrollo Social de la CEPAL.
Este artículo busca sistematizar la información relativa al trabajo femenino urbano en América Latina en los años noventa y contribuir así a un diagnóstico actualizado de la situación laboral femenina, con miras a la formulación de políticas para la mujer. El artículo examina la evolución del trabajo femenino, analiza los efectos que tuvo la crisis de comienzos de los años ochenta en este sector laboral, y pasa revista a los cambios producidos en él, que han ido restando validez a algunos mitos sobre el tema. Examina también algunos aspectos críticos del trabajo femenino, como los ingresos; la segmentación de las ocupaciones; la incorporación segregada de las mujeres en ocupaciones con nueva tecnología, y los procesos de precarización del trabajo femenino, que se traducen en los trabajos a domicilio y por cuenta propia. Finalmente, analiza la situación de un sector de trabajadoras habitualmente en situación precaria, como es el de las trabajadoras del hogar. La fuente de la información estadística presentada son las encuestas de hogares de 1980 y 1990 en trece países de la región, a los que corresponde más del $80 \%$ de la población de América Latina. Del análisis surgen lineamientos de política respecto del mercado de trabajo, el sistema educacional, la familia y la sociedad, con miras a mejorar la condición de las mujeres que trabajan y aprovechar mejor los recursos humanos femeninos. Esto en un nuevo escenario regional, que valora cada vez más el cambio técnico, la innovación, el valor agregado intelectual y la flexibilidad para adaptarse a esa realidad, que posibilitará una efectiva inserción en el desarrollo. 


\section{I}

\section{Introducción}

La elaboración de políticas sociales se basa en el conocimiento y las hipótesis de la realidad social que surgen de la investigación. El diseño de políticas se prueba en la realidad, o mejor dicho, permite comprobar las hipótesis que se tiene sobre esa realidad, al mismo tiempo que influye en ella y la modifica. Estos cambios deben registrarse si se desea desarrollar una política pública eficaz y eficiente. Un diagnóstico actualizado sobre la realidad es fundamental para la formulación de las políticas sociales y económicas; más aún, las políticas públicas deben formularse desde la perspectiva de sociedades compuestas por hombres y mujeres que se comportan de manera diferente en distintas etapas de su ciclo de vida, y teniendo en cuenta las necesidades que tales condiciones determinan.

Este artículo sistematiza, a través de tabulados especiales de las encuestas de hogares, la información relativa al trabajo femenino urbano en América Latina en los años noventa. Busca elaborar un diagnóstico actualizado de la situación laboral femenina y los principales cambios observados en ella entre los años ochenta y noventa, como un aporte a la formulación de políticas dirigidas a la mujer.

En la sección II se examina la evolución del trabajo femenino, analizando los efectos de la crisis de comienzos de los años ochenta. En la sección III se pasa revista a los cambios producidos en el sector laboral femenino, que han transformado en mitos muchas de las aseveraciones hasta ahora en boga sobre el tema. En la sección IV se pasa revista a los aspectos más preocupantes del trabajo femenino, a saber: los ingresos; la segmentación de las ocupaciones; la incorporación segregada de las mujeres en ocupaciones con nuevas tecnologías; los procesos de precarización del trabajo femenino, traducidos en trabajos a domicilio y por cuenta propia, y la situación de un sector de trabajadoras habitualmente en situación precaria, como es el de las trabajadoras del hogar.

La información estadística presentada se basa en las encuestas de hogares de trece países de la región realizadas en 1980 y 1990 , que corresponden a más del $80 \%$ de la población de América Latina. Estas encuestas han sido procesadas y estandarizadas por la División de Estadística y Proyecciones Económicas de la CEPAL. El diseño de los tabulados especiales y la elaboración final de los mismos estuvo a cargo de la autora. Como la mayoría de las encuestas no tenía cobertura nacional, para hacerlas comparables entre sí se han considerado las áreas urbanas de los países. Por la misma razón, la población económicamente activa considerada es la de 15 años y más.

El análisis de esta información sugiere diversas líneas de política respecto del mercado de trabajo, el sistema educacional, la familia y la sociedad. Se trata no sólo de mejorar la condición de las mujeres que trabajan, sino de lograr un uso más eficiente de los recursos humanos femeninos. Este aspecto es central en un nuevo escenario regional, en el cual el cambio técnico, la innovación y el valor agregado intelectual marcarán cada vez más el mercado laboral, y la flexibilidad para adaptarse a esa realidad posibilitará una efectiva inserción en el desarrollo.

\section{II}

\section{Los cambios en el trabajo femenino: la crisis y sus efectos}

Las relaciones de género están fuertemente afectadas por el Estado y el mercado, en juego con los

$\square \quad$ La autora agradece los comentarios de Thelma Gálvez (INE), Virginia Guzmán y Rosalba Todaro (SEM) y Petra Ulshoeser (OIT), y diversos dinamismos de los sustratos culturales existentes. Estas instituciones crean las bases ma-

de las colegas de la CEPAL, eximiéndolas de toda responsabilidad por las deficiencias que pueda contener la investigación. 
teriales que organizan la vida cotidiana de las personas. En la región, la reducción de las regulaciones y el mayor papel del mercado en la asignación de recursos están afectando marcadamente el funcionamiento del mercado de trabajo y las relaciones laborales, así como la orientación de las políticas de empleo, salarios y seguridad social. Examinaremos aquí algunos aspectos del mercado de trabajo y sus efectos en las mujeres durante el período de crisis y ajuste estructural.

Los principales cambios derivados de la crisis y las políticas de ajuste se manifestaron en los ámbitos doméstico y productivo, y en forma diferente para hombres y mujeres. En el sector productivo aumentaron la participación de las mujeres en el mercado de trabajo y el número de horas que ellas destinaban al trabajo remunerado. Pese a la crisis -0 más precisamente a causa de ella- más mujeres se incorporaron al mercado laboral (con comportamientos anticíclicos). La tasa de participación femenina se elevó y aumentó también el desempleo femenino, especialmente entre las más jóvenes. Por lo demás, como gran parte de la mano de obra femenina se ocupa en los sectores no estructurados y de baja productividad, no sólo se ve afectada por las acciones dirigidas específicamente a las trabajadoras, sino también por las medidas dirigidas a los sectores en que se inserta. Desde esa perspectiva, la reducción del tamaño del Estado significó una disminución del empleo estatal para las mujeres, de manera que la desigualdad preexistente fue causa de los efectos diferenciados de la crisis sobre hombres y mujeres, y a la vez la consecuencia más profunda de la crisis fue la perpetuación de esa desigualdad.

La necesidad de subsistencia de los sectores populares tuvo diversos efectos dentro de la familia. $\mathrm{La}$ necesidad de reproducción de la unidad familiar reforzó la interdependencia de sus miembros, en tanto que la estructura familiar sufrió modificaciones de cierta complejidad que no mostraron tendencias claras, ya que en ciertos casos la familia se contrajo y en otros se expandió con "allegados" que contribuyeron a la subsistencia del núcleo familiar. Lo observado en distintos países de América Latina indica que las mujeres aumentaron su participación laboral, al igual que los niños y los jóvenes.

Un estudio sobre México muestra que la reestructuración de la economía mexicana tras la crisis de la deuda, así como las consecuentes políticas de ajuste, forzaron también una reestructuración de la vida cotidiana. La mayoría de las familias sobrevivió a la crisis haciendo un enorme esfuerzo, en el cual todos los miembros participaron a través de nuevas combinaciones de trabajo para el autoconsumo y trabajo para la obtención de un ingreso. Aumentó así la participación de los miembros de la familia en el trabajo para el mercado, pero al mismo tiempo se intensificó el trabajo en actividades reproductivas; el resultado fue una desigual distribución de la carga dentro del hogar, donde las mujeres debieron asumir el mayor peso. La paradoja de esta estrategia es que permitió la continuidad de las políticas de ajuste con grandes costos sociales (Benería, 1992).

Otro de los efectos más evidentes de la crisis fue el creciente desempleo de la población en general, de la femenina en particular y, más precisamente, de la población femenina joven. Aunque el desempleo femenino en la región responde a una tendencia estructural, los efectos de la crisis lo acentuaron fuertemente. El mayor desempleo femenino en América Latina obedece a los siguientes factores estructurales: insuficiencia del dinamismo económico para absorber una mano de obra disponible cada vez mayor, acentuado por la crisis; dificultades de inserción de las mujeres por la segmentación ocupacional del mercado de trabajo, que limita el número de ocupaciones a las que ellas pueden optar; la percepción generalizada entre los empleadores de que el trabajo femenino tiene más interrupciones, debidas al embarazo y crianza, y la falsa idea que el aporte de las mujeres no es central en los ingresos familiares. Los datos para los años noventa indican que en 12 países de la región las tasas de desempleo juvenil casi duplicaron las tasas de desempleo total, en tanto que las tasas de desempleo juvenil femenino fueron superiores a las tasas de desempleo juvenil masculino, salvo en Chile y Paraguay, cuyas economías se hallaban en una fase de crecimiento (CEPAL, 1993). Sin embargo, la información sobre 1992 indica que en Chile las tasas de desempleo femenino para el grupo de edad de 15 a 24 años eran superiores a las de desempleo masculino (SERNAM, 1993).

En cuanto a los efectos de la crisis sobre el trabajo doméstico no remunerado, estudios realizados en diversos países de la región indican que el trabajo femenino aumentó para suplir la ausencia o baja de los ingresos familiares, y para enfrentar el alza de los precios de los alimentos y artículos de primera necesidad y la reducción de los presupuestos de los servicios sociales, que se tradujo en un deterioro de los servicios de salud, educación y vivienda. Un estudio mundial basado en información respecto de 17 países 
-entre ellos Argentina, Brasil, Colombia, Chile, Jamaica, México y Perú- muestra que la aplicación de políticas de ajuste estructural ha provocado un deterioro notable en la relación varones/mujeres en todos los niveles de enseñanza, y especialmente en la enseñanza media, sobre todo en perjuicio de niñas pertenecientes a familias rurales y urbanas marginales; también da cuenta, sobre la base de algunos estudios de casos, de un aumento de la prevalencia de la desnutrición más alta en el caso de las muchachas que de los muchachos (Naciones Unidas, 1989).

Un aspecto poco analizado son los cambios de las fronteras entre los ámbitos de acción del Estado, de la sociedad civil y de las familias, que la crisis ha puesto de relieve en las sociedades latinoamericanas. Durante largos años se tendió a traspasar funciones del ámbito privado al público: un ejemplo claro es el de la atención de los niños menores, que tiende a pasar de las madres a una educadora de párvulos en el jardín infantil. Sin embargo, con la crisis muchas actividades desarrolladas en el ámbito público pasaron a "privatizarse": es decir, al restringirse los presu- puestos en los sectores de salud y educación, entre otros, las responsabilidades retornaron a las familias $y$, por lo tanto, a las mujeres en sus hogares. Siguiendo con el mismo ejemplo, la caída de los ingresos familiares y la insuficiencia crónica de recursos públicos para la atención preescolar gratuita obligó a las familias, y especialmente a las madres, a hacerse cargo nuevamente de los niños pequeños o a buscar en forma comunitaria o aislada soluciones para el cuidado infantil. Fruto de la deficiencia del Estado en la atención de los niños preescolares surgieron interesantes iniciativas, ${ }^{1}$ las que han tenido además efectos no buscados: la necesidad de las mujeres de organizarse frente a estos problemas ha significado una ruptura de su aislamiento y una valoración de su potencial, y a la vez ha hecho más visible su trabajo. Estos cambios en las fronteras de las relaciones entre los ámbitos público y privado, que varían de un país a otro, son un campo poco explorado de las relaciones de género. Sería necesario un enfoque integrado que permitiera visualizar en forma más precisa estos movimientos.

\section{III}

\section{Las mujeres en los años noventa:} mitos y evidencias

Junto con los grandes cambios en los indicadores macroeconómicos y los efectos de la crisis y el ajuste, las tendencias estructurales han modificado la vida de las mujeres latinoamericanas por el aumento en la esperanza de vida, el mayor nivel de educación alcanzado, y la tendencia a tener menos hijos. Estos aspectos han influido en su participación laboral, la que ha aumentado en forma sostenida y se ha manifestado en un aumento de los años de vida económicamente activa de las mujeres. Así, entre 1970 y 1990 la esperanza de vida de las mujeres en la región aumentó en siete años, su tasa global de fecundidad bajó de 5.0 a 3.1 y su vida económicamente activa se alargó en algo más de cinco años (CELADE, 1989 y 1993). A la vez, muchas mujeres migraron a las ciudades en busca de trabajo remunerado, sumándo-

\footnotetext{
1 Por ejemplo, la Asociación de Madres Comunitarias de Colombia (AmColombia). Para mayores antecedentes, véase Mujer/ Fempress, 1994.
}

se así a una población urbana que pasó del $58 \%$ al $73 \%$ de la población total entre 1970 y 1990 (CELADE, 1991).

Si bien estos datos indican un proceso de cambio importante en esos veinte años, no expresan la magnitud y la calidad de los cambios a los que las mujeres han estado expuestas. Tal vez habría que plantearse para la región - al igual que se hace para España (Garrido, 1992) - la coexistencia de dos biografías sociales, con mundos muy dispares: la de la población que tiene más de 50 años y la de la población menor de esa edad. La distancia que media entre dos generaciones de mujeres -madres e hijas- aparece muy amplia con sólo examinar dos indicadores: el nivel de instrucción y la participación laboral. El punto de quiebre entre estos dos mundos pareciera situarse en los años setenta. Metodológicamente, y en este contexto, la variable edad, y aún más la dimensión generacional, cobran enorme capacidad explicativa. El quiebre señalado crea incertidumbre sobre las tra- 
yectorias laborales, puesto que si persisten las tendencias estructurales al aumento de la participación femenina, esta dimensión generacional perderá importancia.

Entre los fenómenos nuevos más notorios en las sociedades latinoamericanas está la presencia creciente de las mujeres en el mercado de trabajo. Esta tendencia es especialmente marcada entre las mujeres jóvenes, cuyas tasas de participación y también de desempleo son de las más altas. Por su parte, la participación de las mujeres de edades intermedias aumentó apreciablememte durante el período 1980-1990. Sin embargo, pese al aumento generalizado de la participación femenina (excepto en las áreas urbanas de Panamá) y la disminución o mantención de la participación masculina, la brecha entre ambos sexos sigue siendo bastante amplia. La información proveniente de las encuestas de hogares (cuadro 1) muestra que las tasas de actividad femenina en las áreas urbanas fluctúan entre $34 \%$ en Chile y $50 \%$ en Paraguay, en tanto que las tasas de actividad masculina se mueven entre $73 \%$ en Bolivia y $84 \%$ en Paraguay y Guatemala. En Panamá se observan descensos tanto de la participación femenina como de la participación masculina en el mercado de trabajo, probablemente producto del desaliento frente a las altísimas tasas de desempleo: de alrededor de $22 \%$ para las mujeres y de $17.2 \%$ para los hombres.

CUADRO 1

América Latina: Tasas de participación por sexo, 1980 y $1990^{\circ}$

(Porcentajes)

\begin{tabular}{|c|c|c|c|c|}
\hline \multirow[t]{2}{*}{ País } & \multicolumn{2}{|c|}{$\begin{array}{c}\text { Población } \\
\text { económicamente activa } \\
\text { femenina }\end{array}$} & \multicolumn{2}{|c|}{$\begin{array}{c}\text { Población } \\
\text { económicamente activa } \\
\text { masculina }\end{array}$} \\
\hline & 1980 & 1990 & 1980 & 1990 \\
\hline Argentina & 32.4 & 38.2 & 75.6 & 75.7 \\
\hline Bolivia & $\ldots$ & 46.6 & $\ldots$ & 73.3 \\
\hline Brasil & 37.2 & 45.1 & 81.5 & 82.5 \\
\hline Colombia & 41.8 & 45.7 & 79.3 & 79.2 \\
\hline Costa Rica & 33.6 & 39.1 & 77.6 & 77.6 \\
\hline Chile & $\ldots$ & 34.0 & $\ldots$ & 73.2 \\
\hline Guatemala & $\ldots$ & 42.9 & $\ldots$ & 84.4 \\
\hline Honduras & $\ldots$ & 43.4 & $\ldots$ & 80.2 \\
\hline México & $\ldots$ & 35.9 & $\ldots$ & 77.3 \\
\hline Panamá & 44.5 & 42.8 & 76.2 & 75.6 \\
\hline Paraguay & & 49.7 & & 84.2 \\
\hline Uruguay & 37.3 & 43.8 & 74.6 & 74.7 \\
\hline Venezuela & 31.2 & 37.5 & 78.4 & 77.9 \\
\hline
\end{tabular}

Fuente: CEPAL, División de Desarrollo Social y División de Estadística y Proyecciones Económicas, sobre la base de tabulados especiales de encuestas de hogares.

a Población de áreas urbanas de 15 años y más.

La información para las áreas urbanas muestra que las mayores tasas de actividad económica femenina se encuentran en las edades intermedias de 20 a 54 años. En el grupo de mujeres de 25 a 29 años (con mayor proporción de económicamente activas) las tasas de participación fluctuaban entre $45 \%$ en México y $71 \%$ en Uruguay. Las mujeres sobre los 55 años, específicamente las mujeres entre 60 y 64 años (que arrastran una tendencia histórica de no participación) y las muy jóvenes, menores de 20 años (que aún permanecen en el sistema educacional y que tienen dificultades para encontrar empleo) son las que muestran los niveles más bajos de participación laboral. Es decir, más que establecer una relación directa entre participación y edad, lo que debe hacerse es distinguir entre la actividad de dos generaciones de mujeres.

El sentido común y algunos estudios referidos al decenio de 1970 en otras regiones o en América Latina han sustentado diversas aseveraciones sobre la participación laboral femenina que, según la información recogida en las áreas urbanas de la región para los años noventa, hoy no son más que mitos (es decir, creencias que, sin tener base en la reali- 
dad, sirven de sustrato para la construcción de prejuicios).

Estos mitos han surgido producto de dos desfases: un desfase temporal entre el conocimiento de una realidad y los cambios en esa realidad, y un desfase de contexto, que resulta de aplicar a un contexto una constatación empírica hecha en otro. A continuación se examinan algunos de ellos.

Mito 1. La participación femenina tiene forma de $U$ invertida

Una creencia muy común -basada en experiencias del mundo desarrollado- apunta a que la participación de las mujeres tiene forma de $\mathrm{U}$, con dos momentos en que aumenta al máximo: la participación es mayor antes del nacimiento del primer hijo, y cuando el hijo menor empieza a asistir a la escuela. ${ }^{2}$ Un análisis de la participación femenina por grupos de edades que permite aproximarse a través de las cohortes de edad a la evolución laboral de distintos grupos de mujeres, muestra que en los años noventa, en 13 áreas urbanas de América Latina, la participación femenina ha aumentado sostenidamente entre los 15 y los 54 años y ha bajado fuertemente en los grupos de edad mayores; esto indica que las mujeres urbanas que entran al mercado laboral no se retiran cuando tienen hijos y que se mantienen económicamente activas durante todo el período de mayor trabajo reproductivo. Esta tendencia se acentuó entre los años ochenta y noventa (cuadro 2). Los mayores aumentos en la participación femenina se produjeron en los grupos de 25 a 34 años y de 35 a 44 años.

Un estudio reciente realizado en Argentina tiende a confirmar la dirección de este cambio, ya que muestra un crecimiento mayor de la participación laboral de las mujeres casadas que de las mujeres solteras (Montoya, 1993). Este mismo fenómeno se observa en México; sobre la base de las encuestas de fecundidad, se concluye que allí la participación en la fuerza de trabajo de las mujeres casadas o en unión consensual de 20 a 49 años aumentó en $62 \%$ entre 1976 y 1987 (García y Oliveira, 1993). En Uruguay, la categoría de mujeres que más incrementó su participación fue la de las casadas y en unión consensual, seguida por las divorciadas, separadas y viudas, quedando en último lugar las solteras (Filgueira, 1992). Estos cambios involucran a su vez modificaciones importantes en la organización de la vida cotidiana de los hogares, y en la magnitud del trabajo requerido dentro y fuera del hogar.

CUADRO 2

América Latina: Tasas de actividad económica femenina para algunos grupos de edades en zonas urbanas, 1980 y 1990

(Porcentajes)

\begin{tabular}{|c|c|c|c|c|c|c|}
\hline \multirow{2}{*}{ País } & \multicolumn{2}{|c|}{ 15-24 años } & \multicolumn{2}{|c|}{ 25-34 años } & \multicolumn{2}{|c|}{$35-44$ años } \\
\hline & 1980 & 1990 & 1980 & 1990 & 1980 & 1990 \\
\hline Argentina & 44.9 & 41.1 & 45.4 & 52.5 & 42.7 & 52.9 \\
\hline Bolivia & $\ldots$ & 33.8 & $\ldots$ & 56.7 & $\ldots$ & 62.0 \\
\hline Brasil & 42.9 & 48.1 & 43.9 & 55.7 & 42.3 & 55.3 \\
\hline Colombia & 42.4 & 41.2 & 52.1 & 61.2 & 49.2 & 56.8 \\
\hline Costa Rica & 33.2 & 39.2 & 45.6 & 52.6 & 44.4 & 51.8 \\
\hline Chile & $\ldots$ & 26.4 & $\ldots$ & 46.1 & $\ldots$ & 46.8 \\
\hline Guatemala & $\ldots$ & 42.1 & $\ldots$ & 50.1 & $\ldots$ & 50.0 \\
\hline Honduras & $\ldots$ & 34.5 & $\ldots$ & 53.8 & $\ldots$ & 57.2 \\
\hline México & $\ldots$ & 36.4 & $\ldots$ & 44.6 & $\ldots$ & 42.3 \\
\hline Panamá & 40.0 & 35.5 & 63.3 & 58.7 & 58.3 & 60.6 \\
\hline Paraguay & $\ldots$ & 50.6 & . & 62.8 & & 61.4 \\
\hline Uruguay & 43.2 & 46.5 & 56.6 & 69.3 & 54.5 & 65.7 \\
\hline Venezuela & 25.7 & 24.8 & 42.6 & 50.8 & 42.0 & 53.7 \\
\hline
\end{tabular}

Fuente: CEPAL, División de Desarrollo Social y División de Estadística y Proyecciones Económicas, sobre la base de encuestas de hogares de los respectivos países.

\footnotetext{
2 Véase al respecto las curvas estilizadas para países industrializados y para América Latina elaboradas por Psacharopoulos y Tzannatos (1992, p. 17).
} 


\section{Mito 2. El trabajo femenino es secundario}

Según otro mito muy generalizado, el trabajo femenino es secundario, está sujeto a los vaivenes cíclicos de la economía y sólo se acude a él en épocas de crisis, para complementar el presupuesto familiar.

Desde los años ochenta el porcentaje de hogares encabezados por mujeres que constituyen el único aporte del hogar alcanza magnitudes importantes: entre un cuarto y un tercio de los hogares. ${ }^{3}$ Habría que agregar que existen además hogares - no detectados en los censos de población ni en las encuestas de hogares por la definición de jefatura utilizada - donde el aporte de la mujer es igual o superior al del hombre. Un estudio realizado en el área metropolitana de Buenos Aires, que examinó a fondo este tema, encontró que la proporción de hogares que tenían a una mujer como principal sostén económico pasó de $19 \%$ en 1980 a 25\% en 1989 (Geldstein, 1992). De otro lado, en los países en que el proceso de estabilización se empieza a marcar más fuertemente y las condiciones de empleo han mejorado para los hombres, no se aprecia un retiro de las mujeres del mercado de trabajo, como ocurriría si las mujeres fuesen efectivamente mano de obra secundaria.

\section{Mito 3. Las mujeres reciben menos ingresos porque tienen menor nivel de instrucción}

Está extendida la creencia de que las mujeres ganan menos que los hombres porque su nivel de instrucción o experiencia es menor. Algunos estudios de tipo cualitativo que analizan las trayectorias laborales muestran que hombres y mujeres con niveles de calificación similares parten de niveles de ingresos semejantes; con el desarrollo profesional esas trayectorias tienden a distanciarse, ya que los hombres rápidamente escalan posiciones de mayores ingresos,

\footnotetext{
${ }^{3}$ En 1980 el porcentaje de hogares encabezados por mujeres era el siguiente: Antillas Neerlandesas $30 \%$, Barbados $44 \%$, Cuba $26 \%$, Chile $22 \%$, Dominica $38 \%$, El Salvador $22 \%$, Granada $45 \%$, Guadalupe $34 \%$, Guyana $24 \%$, Honduras $22 \%$, Jamaica $34 \%$, Martinica $35 \%$, Panamá $22 \%$, Perú $23 \%$, San Vicente y las Granadinas $42 \%$, Santa Lucía $39 \%$, St. Kitts y Nevis $46 \%$, Trinidad y Tabago $25 \%$, Uruguay $21 \%$ y Venezuela $22 \%$ (Naciones Unidas, 1991). La información sobre 1990 de las encuestas de hogares arroja para las zonas urbanas los siguientes valores: Argentina $21 \%$; Bolivia $16.7 \%$; Brasil 20.1\%; Colombia $22.6 \%$; Costa Rica 22.6\%; Chile 23.2\%; Guatemala 20.8\%; Honduras 26.6\%; México $17.7 \%$; Panamá $24.7 \%$; Paraguay $19.7 \%$; Uruguay $25.2 \%$ y Venezuela $22.1 \%$.
}

prestigio y poder, en tanto que las mujeres se mantienen en los mismos puestos. Estudios recientes muestran que, aun manteniendo constantes el número de horas trabajadas y el nivel de instrucción, hay una porción muy importante de la diferencia de ingresos entre hombres y mujeres que no queda explicada (Psacharopoulos y Tzannatos, 1992).

La información estadística indica que las mujeres tienen un nivel de instrucción en promedio mayor que los hombres en el mercado laboral. Tanto en los años ochenta como actualmente los salarios que las mujeres perciben son notablemente más bajos que los masculinos, cualquiera sea el grado de instrucción que ellas tengan. En el decenio de 1980 la disparidad de ingresos entre hombres y mujeres tendió a mejorar en cuatro países y empeoró en dos (Costa Rica y Uruguay), pero si se introduce la variable educación la situación cambia. En el nivel de menor instrucción (menos de tres años de enseñanza) la relación mejoró en todos los casos; sin embargo, en el nivel de mayor instrucción (sobre 13 años) la distancia entre los salarios femeninos y masculinos vuelve a aumentar en las áreas urbanas de Costa Rica, Uruguay y Venezuela. De esta forma, al comparar la información de 1980 con la de 1990 la mayor diferencia de ingresos se produce en los niveles de instrucción más altos (cuadro 3).

Asombra comprobar que aun cuando las mujeres con elevados niveles de instrucción reciben salarios muy por debajo de los masculinos, la participación laboral femenina se mantiene casi en magnitudes similares a la de los hombres cuando tienen más de 13 años de instrucción. Este hallazgo plantea dudas en relación con los análisis neoclásicos de costo-beneficio como determinantes en la "opción" de trabajar de las mujeres. En este sentido, sería muy interesante estudiar el comportamiento laboral femenino por grupos socioeconómicos y por características de los hogares, ya que sólo en los grupos de mayores ingresos las mujeres pueden plantearse el trabajo como opción. Tal vez habría que explorar más la segregación del mercado de trabajo que ubica a las mujeres en un número limitado de ocupaciones, lo que algunos autores interpretan como "preferencias" de las mujeres por determinadas ocupaciones.

Mito 4. La mayoría de las mujeres latinoamericanas son dueñas de casa y tienen muchos hijos

En el imaginario de la región está el mito de que las mujeres latinoamericanas son en su mayoría due- 
CUADRO 3

América Latina: Diferencias de ingreso por sexo en algunos niveles de instrucción, a 1980 y 1990

(Porcentajes)

\begin{tabular}{|c|c|c|c|c|c|c|}
\hline \multirow{2}{*}{ País } & \multicolumn{2}{|c|}{ Total } & \multicolumn{2}{|c|}{$\begin{array}{l}0-3 \text { años de } \\
\text { instrucción }\end{array}$} & \multicolumn{2}{|c|}{$\begin{array}{l}13 \text { y más años de } \\
\text { instrucción }\end{array}$} \\
\hline & 1980 & 1990 & 1980 & 1990 & 1980 & 1990 \\
\hline Argentina & 63.5 & 68.8 & $\ldots$ & & $\ddot{*}$ & \\
\hline Bolivia & & 57.4 & . & 58.4 & . & 46.0 \\
\hline Brasil & 46.3 & 56.0 & 41.0 & 45.8 & 38.8 & 50.7 \\
\hline Colombia & 56.1 & 66.7 & 51.0 & 58.8 & 55.0 & 60.4 \\
\hline Costa Rica & 80.6 & 71.0 & 48.2 & 51.3 & 86.4 & 64.2 \\
\hline Chile & $\ldots$ & 59.2 & $\ldots$ & 67.7 & $\ldots$ & 41.9 \\
\hline Guatemala & $\ldots$ & 65.8 & $\ldots$ & 45.4 & $\ldots$ & 64.2 \\
\hline Honduras & $\ldots$ & 57.9 & $\ldots$ & 49.9 & $\ldots$ & 51.5 \\
\hline México & $\ldots$ & 68.2 & $\ldots$ & 63.8 & $\ldots$ & 61.2 \\
\hline Panamá & $\ldots$ & 77.0 & $\ldots$ & 46.1 & $\ldots$ & 68.4 \\
\hline Paraguay & $\ldots$ & 56.7 & $\ldots$ & 64.0 & $\ldots$ & 47.1 \\
\hline Uruguay & 53.9 & 44.3 & 46.6 & 50.1 & 44.0 & 37.3 \\
\hline Venezuela & 67.8 & 72.7 & 56.3 & 64.0 & 71.1 & 68.0 \\
\hline
\end{tabular}

Fuente: CEPAL, División de Desarrollo Social y División de Estadística y Proyecciones Económicas sobre la base de las encuestas de hogares de los respectivos países.

a Ingreso medio femenino como porcentaje del ingreso medio masculino. Población de áreas urbanas de 15 años y más.

ñas de casa y que, como tienen muchos hijos a su cargo, no pueden trabajar fuera de su hogar. La información proveniente de las encuestas de hogares de los años noventa permite mostrar un panorama bastante distinto. En primer lugar, la proporción de mujeres que son dueñas de casa es muy variable en 13 ciudades y áreas urbanas de la región. Las mujeres que se declaran dueñas de casa van desde el $20 \%$ (en Montevideo) hasta el $49 \%$ (en Santiago de Chile). ${ }^{4}$ Sólo a partir de los 45 años la mayoría de las mujeres se declara dueña de casa. Además, como se indicó antes, la tasa de fecundidad (para áreas urbanas y rurales) ha disminuido en la región y la estimación de la fecundidad para el quinquenio 1990-1995 es de 3.1 (CELADE, 1993). La caída de la fecundidad urbana es mayor, puesto que esta estimación incluye los países de la región en su conjunto y por tanto a las áreas rurales, donde las tasas de fecundidad son mucho más altas.

Mito 5. Las mujeres latinoamericanas que trabajan cuentan con trabajadora del hogar

Un mito complementario del anterior indica que la creciente participación laboral femenina ha sido

\footnotetext{
${ }^{4}$ Las magnitudes para las áreas urbanas son las siguientes: Argentina $37 \%$; Bolivia 29\%; Brasil $41 \%$; Colombia $39 \%$; Costa Rica 42\%; Chile 49\%; Guatemala $46 \%$; Honduras $40 \%$; México
}

permitida por la existencia de trabajadoras del hogar. Si bien en comparación con regiones desarrolladas la proporción de mujeres que son trabajadoras del hogar en América Latina es mucho mayor --entre un décimo y un cuarto del total de la ocupación femenina, según el país-, ${ }^{5}$ la proporción de mujeres que trabajan es mucho mayor aún. Además, también cuentan con trabajadoras del hogar muchas dueñas de casa que no laboran fuera de la casa. Por último, la magnitud de mujeres ocupadas como trabajadoras del hogar está decreciendo, en tanto que aumenta la participación laboral de las mujeres, especialmente las casadas y con hijos. De esta forma, si bien hay una proporción de hogares de mujeres que trabajan fuera del hogar y que cuentan con trabajadoras del hogar para atender a la familia, cada vez hay más mujeres que deben realizar dos jornadas de trabajo. Esto tiene consecuencias importantes que deben contemplarse en el diseño de políticas para las trabajadoras.

En suma, la información estadística para los años noventa revela que la mayoría de las mujeres latinoamericanas participa en el mercado de trabajo, especialmente en las edades intermedias de 20 a 45 años, con niveles educativos altos y con ingresos muy por

$48 \%$; Panamá $36 \%$; Paraguay $36 \%$; Uruguay $20 \%$ y Venezuela $46 \%$.

${ }^{5}$ Respecto de las trabajadoras del hogar véase la sección IV, apartado 4 a). 
debajo de los masculinos, cualquiera sea el nivel de instrucción considerado. Muestra además que los cambios ocurridos en el mercado laboral femenino urbano destruyen algunos mitos acerca del trabajo femenino.

Subsisten otras muchas creencias de índole similar que la información de las encuestas de hogares no permite verificar o desvirtuar, y que sería interesante investigar con otros instrumentos para comprobar si son efectivas: por ejemplo, que hay mayor ausentismo laboral femenino por el cuidado de los hijos; que las mujeres trabajan menos horas que los hombres, y que el costo de la trabajadora mujer es mayor que el del trabajador hombre por los costos de guarderías y permisos prenatales y posnatales. Esto último no parece tener en cuenta que los ingresos percibidos por las trabajadoras - casadas o solteras, con o sin hijos- son muy inferiores a los de los hombres. El dinamismo observado en la situación del trabajo femenino hace cada vez más necesario comprobar empíricamente esta y muchas otras afirmaciones.

La mayoría de los análisis cuantitativos de la participación laboral de las mujeres establece los efectos que esta participación tiene en sus vidas; sin embargo, poco se han investigado los nuevos sentidos y las modificaciones que, al incorporarse al mundo laboral, introducen las mujeres en éste. Se ha planteado que el salto de las mujeres de la casa a la calle significa el paso de una lógica familiar doméstica a la adquisición de una nueva lógica mercantil. Pero lo más interesante es que las mujeres también llegan al mundo del trabajo portando criterios del mundo privado, y valores tales como los afectivos, que se manifestarán por el grado de satisfacción laboral que les proporcione el trato y el reconocimiento que reciban. Este enfoque del trabajo por parte de las mujeres y sus tentativas conscientes o inconscientes de desviar algunas de sus normas, introduciendo connotaciones de lo privado, esbozan una crítica a la separación entre el trabajo y la vida, que ofrece un considerable potencial político de transformación (Aranda, 1991; Darcy de Oliveira, 1989). Esta apreciación debería matizarse con la diversa inserción de las mujeres en el mundo laboral (el grado de poder al que acceden), con el tipo de ocupaciones en que se desempeñan (más o menos feminizadas, más o menos modernas), así como con la modalidad de trabajo escogida. En este sentido, analizar en mayor profundidad el trabajo por cuenta propia - que ha aumentado en los últimos años- permitiría confirmar si éste consti- tuye una opción por la mayor flexibilidad de horario que ofrece, o porque también es la opción más semejante al trabajo que realizan las mujeres como dueñas de casa, lo que facilitaría su paso del hogar al trabajo remunerado.

Algunos elementos derivados de los análisis cualitativos realizados en las empresas muestran que, al incorporarse las mujeres en sitios de trabajo masculinos, hay un cambio en el lenguaje de los trabajadores, si bien en el proceso de modernización se mantiene la "cultura" de la empresa, donde sólo se cambian las formas de reproducción de la discriminación hacia la mujer. Este fenómeno se produce especialmente a través de las prácticas de selección, contratación, evaluación y promoción de personal que tienen las organizaciones (Hola y Todaro, 1992). Tan fuerte es el sello masculino, que si la mujer que ingresa a la empresa desea ser escuchada y comprendida, debe realizar un esfuerzo especial para expresarse en un lenguaje que concuerde con el modelo vigente en ese espacio social y no con su propia manera de pensar y sentir. Actualmente, en las empresas modernas se está planteando el rescate y una nueva valoración de elementos "femeninos", que apuntan a una organización empresarial más eficiente - como capacidad de negociación, mejor relación con las personas, mayor compromiso y cumplimiento de tareas, etc.-, elementos que en otro contexto han servido como base para la exclusión de las mujeres de ciertos puestos dentro de la empresa.

A través de estudios en profundidad se podría saber si la concentración de las mujeres en sectores feminizados está determinada sólo desde el lado de la demanda de la mano de obra femenina o si, por el contrario, parte de esta concentración es una opción de las propias mujeres frente a los obstáculos que deben enfrentar para ingresar a ocupaciones no feminizadas. Entre esos obstáculos se cuentan las prácticas empresariales de reclutamiento, la estructura jerárquica de los cargos y la estructura de salarios, las formas de evaluación del desempeño ocupacional y el acceso a la formación y capacitación profesional (Rico, 1994). Para romper con la segmentación ocupacional por género dentro de las ocupaciones y tender a una participación laboral no sesgada es preciso ante todo identificar claramente los obstáculos que enfrentan las mujeres en su desempeño laboral, pero también los elementos que favorecen la mayor participación femenina. De un lado, el aumento de la participación femenina se vio favorecido por la ampliación de puestos en el 
sector terciario en que tradicionalmente se han insertado las mujeres. Queda por investigar si la creciente demanda de recursos humanos polivalentes puede ser un factor que empiece a perfilarse como positivo para las mujeres educadas que se incorporan al mercado de trabajo.

\section{IV}

\section{Aspectos críticos: ingresos, segmentación ocupacional, nuevas tecnologías y precarización de algunos empleos femeninos}

\section{Ingresos}

Las mayores desigualdades entre hombres y mujeres en el mercado de trabajo se hallan en los ingresos. En la diferencia de ingresos entre hombres y mujeres, el porcentaje que se atribuye a discriminación de género varía, según el país, entre 10 y $85 \%$, y tiende a ser mayor que $50 \%$ en los países en desarrollo. Algunos estudios sugieren que en la región la segregación de las ocupaciones y las diferencias de ingresos resultantes son mucho más extremas que en países desarrollados (Barbezat, 1993). Las estimaciones de los efectos que la segregación ocupacional de las mujeres tiene sobre sus ingresos son igualmente variables. Junto con la creciente participación femenina en la fuerza de trabajo, tanto la disparidad de ingresos como el porcentaje de ella que se atribuye a discriminación tienden a declinar con el tiempo. Esta última tendencia, que sólo se ha podido medir en los países desarrollados, está asociada a iniciativas de política gubernamental o sindical a través de convenios colectivos, las que han sido menos exitosas en los países con mercados laborales muy descentralizados, como los Estados Unidos (González, 1992)

En la región, las diferencias de ingresos entre hombres y mujeres confïman la existencia de discriminación salarial en contra de la mujer. En ningún país se paga una remuneración equivalente a hombres y mujeres con el mismo nivel de instrucción. Los ingresos de las mujeres jóvenes o adultas son habitualmente menores que los de los hombres, cualquiera sea el nivel educacional que se considere, y la discriminación se presenta en todos los grupos ocupacionales. La desventaja relativa de los ingresos por hora de las mujeres adultas con respecto de los hombres equivale a alrededor de cuatro años de educación formal (CEPAL, 1993). Si se analiza lo ocurrido en los años ochenta, los datos estadísticos muestran que en los cinco países para los cuales se cuenta con información, la diferencia de salarios entre hombres y mujeres en los niveles de instrucción más bajos mejoró entre 1980 y 1990 , en tanto que en los niveles de instrucción más altos la disparidad aumentó en tres casos y disminuyó sólo en dos (cuadro 3). Una explicación factible de la menor diferencia de salarios a niveles de instrucción más bajos es que los salarios percibidos por las mujeres en esos niveles de instrucción llegaron a un mínimo que hace imposible disminuirlos más.

Información más precisa sobre Costa Rica muestra que la diferencia de salarios se incrementó durante el período de crisis y estabilización (1980-1983) y decreció con la recuperación (1983 a 1986). El aumento de la disparidad entre ingresos masculinos y femeninos durante la recesión (entre 1980 y 1982), se debió principalmente al aumento de la participación laboral de las mujeres menos educadas que ingresaron al mercado laboral en respuesta a la caída de los ingresos reales de los jefes de familia. Estas mujeres se incorporaron en mayor proporción a sectores económicos que pagaban salarios más bajos (Gindling, 1992).

Una investigación publicada recientemente por el Banco Mundial concluye, sobre la base de la información de 15 países de la región para los años 1950 a 1985, que sólo un $20 \%$ de las diferencias de ingreso entre hombres y mujeres puede ser explicado por diferencias de capital humano entre ellos; el resto se explica por factores de discriminación. Luego de corregir esta estimación, teniendo presente la autoselección que las mujeres realizan en el mercado de traba- 
jo (sus opciones laborales), se estima que otro $20 \%$ se explica por el menor poder de generar ingresos que tienen las mujeres, de modo que al final la parte no explicada de las disparidades de ingresos entre hombres y mujeres alcanza a un $60 \%$, cifra mucho más alta que la encontrada para países más avanzados (Psacharopoulos y Tzannatos, 1992). Este 60\% no explicado alude principalmente a los aspectos culturales que segregan el mercado de trabajo en un número limitado de ocupaciones definidas para ser desempeñadas por mujeres.
La información disponible para los años noventa sobre 13 áreas urbanas de la región muestra que el ingreso medio de las mujeres representa entre $44 \%$ y $77 \%$ del de los hombres. Esta disparidad se acentúa aún más a nivel de jefes de hogar: el ingreso medio de las mujeres jefas de hogar es sólo entre el $45 \%$ y el 69\% del de los hombres jefes de hogar (cuadro 4). Esta información apunta nuevamente a la necesidad de políticas sociales y de empleo especiales para estas mujeres, que son quienes muestran los mayores niveles de pobreza.

CUADRO 4

América Latina: Diferencias de ingresos medios por sexo y jefatura de hogar, ${ }^{a} 1980$ y 1990 (Porcentajes) $^{\mathrm{b}}$

\begin{tabular}{|c|c|c|c|c|}
\hline \multirow{2}{*}{ País } & \multicolumn{2}{|c|}{ Mujeres/Hombres } & \multicolumn{2}{|c|}{ Jefas/Jefes } \\
\hline & 1980 & 1990 & 1980 & 1990 \\
\hline Argentina & 63.5 & 68.8 & 70.5 & 69.6 \\
\hline Bolivia & $\ldots$ & 57.4 & $\ldots$ & 56.0 \\
\hline Brasil & 46.3 & 56.0 & 40.2 & 53.2 \\
\hline Colombia & 56.1 & 66.7 & 59.2 & 62.1 \\
\hline Costa Rica & 80.6 & 71.0 & 63.3 & 64.7 \\
\hline Chile & $\ldots$ & 59.2 & $\ldots$ & 56.4 \\
\hline Guatemala & $\ldots$ & 65.8 & $\ldots$ & 62.6 \\
\hline Honduras & $\ldots$ & 57.9 & $\ldots$ & 51.3 \\
\hline México & $\ldots$ & 68.2 & $\ldots$ & 65.9 \\
\hline Panamá & $\ldots$ & 77.0 & $\ldots$ & 64.2 \\
\hline Paraguay & $\ldots$ & 56.7 & $\ldots$ & 54.7 \\
\hline Uruguay & 53.9 & 44.3 & 52.5 & 45.0 \\
\hline Venezuela & 67.8 & 72.7 & 59.2 & 65.6 \\
\hline
\end{tabular}

Fuente: CEPAL, División de Desarrollo Social y División de Estadística y Proyecciones Económicas, sobre la base de encuestas de hogares de los países.

a Población de áreas urbanas de 15 años y más.

b Ingreso medio femenino como porcentaje del ingreso medio masculino para el total de ocupados y para los que son jefes de hogar.

\section{Segmentación de las ocupaciones}

La segregación ocupacional por sexo es un denominador común de los mercados de trabajo en países tanto industrializados como en desarrollo: persiste a través de las décadas y de las fronteras internacionales. En varios países los índices de segregación aumentaron en los años ochenta e incluso en algunos casos se produjo una resegregación de las ocupaciones, con gran segregación vertical dentro de las ocupaciones y dentro de los establecimientos (Barbezat, 1993).

En la región, la segmentación ocupacional por género en el mercado de trabajo se expresa en la concentración ocupacional de las mujeres en un número reducido de ocupaciones que se definen cultu- ralmente como típicamente femeninas (segmentación horizontal). A ella se sumaría una segmentación vertical, puesto que las mujeres se concentran en los niveles de menor jerarquía de cada ocupación, lo que significa puestos de trabajo peor remunerados y más inestables (Abramo, 1993). Un estudio realizado en Perú mostró que en cada industria operaba como principio organizador una estricta división del trabajo, separando y configurando los trabajos femeninos y masculinos, y que había también gran heterogeneidad de situaciones entre las empresas estudiadas (Guzmán y Portocarrero, 1992).

La información disponible para 13 áreas urbanas de la región refleja un proceso de creciente terciarización, ya que las mujeres continúan concentrándose mayoritariamente en el sector de los servicios. Entre 
1980 y 1990 esta rama siguió creciendo y absorbió entre $42 \%$ y $65 \%$ de la mano de obra femenina. ${ }^{6}$

Las ocupaciones que concentran mayor cantidad de mujeres son las de profesionales y técnicas, vendedoras y trabajadoras del hogar. La información para 1990 muestra además que una proporción mayor de mujeres que de hombres se emplea como profesionales y técnicos, en tanto que una mayor proporción de hombres se ocupa como gerentes y obreros. Entre los trabajadores de servicios, según los países, las mujeres duplican o triplican la proporción de hombres. En Venezuela, una de cada cuatro mujeres ocupadas trabaja como profesional o técnica (cuadro 5).

Se ha señalado que en Venezuela el rápido cre- cimiento de los trabajadores con educación universitaria no ha sido acompañado por un aumento de la demanda de ese tipo de trabajadores, lo que ha acarreado un mayor desempleo, un deterioro de los ingresos reales, mayor diferenciación interna y frustración creciente del grupo de profesionales. Las profesionales universitarias se han visto más perjudicadas porque buscaban incorporarse a un mercado en el cual no habían logrado consolidarse previamente en momentos en que éste se expandía en forma lenta. Las mujeres lograron acceder a la educación en cantidad igual que los hombres, pero las credenciales adquiridas no fueron garantía laboral suficiente para ellas (Bonilla, 1992).

CUADRO 5

América Latina: Distribución de la población económicamente activaa en algunas ocupaciones, 1990

(Porcentajes) $^{b}$

\begin{tabular}{|c|c|c|c|c|c|c|c|c|}
\hline \multirow{2}{*}{ País } & \multicolumn{2}{|c|}{$\begin{array}{l}\text { Profesionales } \\
\text { y técnicos }\end{array}$} & \multicolumn{2}{|c|}{$\begin{array}{c}\text { Administradores } \\
\text { y gerentes }\end{array}$} & \multicolumn{2}{|c|}{$\begin{array}{l}\text { Trabajadores } \\
\text { de servicios }\end{array}$} & \multicolumn{2}{|c|}{ Obreros } \\
\hline & Mujeres & Hombres & Mujeres & Hombres & Mujeres & Hombres & Mujeres & Hombres \\
\hline Argentina & $\ldots$ & $\ldots$ & $\ldots$ & $\ldots$ & $\ldots$ & $\ldots$ & $\ldots$ & $\ldots$ \\
\hline Bolivia & 13.8 & 13.5 & 1.8 & 4.7 & 23.3 & 6.3 & 12.4 & 52.9 \\
\hline Brasil & 15.9 & 6.2 & 5.0 & 10.2 & 33.2 & 16.6 & 14.6 & 38.2 \\
\hline Colombia ${ }^{c}$ & 13.6 & 13.3 & $\ldots$ & $\ldots$ & 30.8 & 8.7 & 17.6 & 47.0 \\
\hline Costa Rica & 20.2 & 14.6 & 3.4 & 6.2 & 26.1 & 9.9 & 18.8 & 39.9 \\
\hline Chile & 14.7 & 7.1 & 2.6 & 5.5 & 32.1 & 7.8 & 11.6 & 46.1 \\
\hline Guatemala & 13.9 & 10.1 & 4.8 & 5.9 & 25.1 & 5.5 & 19.1 & 41.1 \\
\hline Honduras & 13.9 & 9.4 & 1.9 & 4.3 & 30.3 & 8.5 & 18.9 & 47.0 \\
\hline México & 17.7 & 11.7 & 1.7 & 4.5 & 23.5 & 7.9 & 13.6 & 48.3 \\
\hline Panamá & 20.2 & 10.8 & 4.0 & 7.8 & 31.4 & 12.0 & 7.8 & 34.8 \\
\hline Paraguay & 13.7 & 8.9 & 1.3 & 4.6 & 36.3 & 9.9 & 12.3 & 44.5 \\
\hline Uruguay & 17.7 & 6.9 & 1.6 & 4.7 & 31.0 & 9.8 & 16.2 & 47.5 \\
\hline Venezuela & 24.5 & 10.0 & 2.2 & 5.3 & 26.6 & 10.0 & 10.1 & 43.2 \\
\hline
\end{tabular}

Fuente: CEPAL, División de Desarrollo Social y División de Estadística y Proyecciones Económicas, sobre la base de encuestas de hogares de los países.

a Población de áreas urbanas de 15 años y más.

b Porcentaje sobre el total de ocupados de cada sexo en cada categoría.

${ }^{c}$ La categoría profesionales y técnicos incluye a administradores y gerentes.

En general, las mujeres se desempeñan en un número más reducido de ocupaciones que los hombres. Un estudio en Chile muestra una mayor concentración ocupacional entre las mujeres que entre los hombres, en determinadas ocupaciones y en ciertos sectores económicos. Una sola ocupación absor-

${ }^{6}$ Las magnitudes para las áreas urbanas son las siguientes: Argentina 66\%; Bolivia 43\%; Brasil 64\%; Colombia 47\%; Costa Rica $53 \%$; Chile 57\%; Guatemala $42 \%$; Honduras $44 \%$; México $52 \%$; Panamá 65\%; Paraguay 55\%; Uruguay 61\% y Venezuela $61 \%$. be en el sector financiero más del $70 \%$ de las mujeres del sector (servicios personales); en el total de los sectores esta concentración baja a $31.3 \%$ de la población femenina ocupada (Hola y Todaro, 1992). En México, al construir un índice de segregación ocupacional por género en los sectores manufacturero, de comercio y de servicios, se encontró el mayor índice de segregación en las fábricas manufactureras, luego en los servicios y finalmente en el comercio (Rendón, 1993). En Chile, en el Gran Santiago, se ha confirmado en la industria manufacturera la se- 
gregación de las mujeres desde tres puntos de vista: i) el tamaño de las empresas: a medida que el tamaño de la empresa aumenta, la participación femenina es menor; ii) la rama industrial: las mujeres se concentran en la industria textil, de vestuario y cueros y de alimentos, bebidas y tabaco, y iii) la categoría ocupacional: la participación femenina se concentra en las áreas administrativas, de venta y de servicios (Abramo, 1993).

\section{Las nuevas tecnologías}

Diversos estudios han señalado que no se perciben efectos sistemáticos de las nuevas tecnologías en la definición de los trabajos y de las fronteras entre ellos, puesto que ellas traen consigo un movimiento de trabajadores, hombres y mujeres, hacia adentro y hacia afuera del mercado de trabajo y entre diferentes tipos de labores. Es necesario, por lo tanto, analizar esos efectos en el corto y largo plazo.

Los efectos estudiados en algunos países de la región muestran que ha habido un aumento de la participación femenina en la banca, los seguros y las finanzas, donde se ha producido un importante cambio tecnológico. Sin embargo, este proceso de incorporación femenina en ocupaciones "modernas" y de altos niveles de sofisticación tecnológica no ha significado una disminución de la segmentación ocupacional. Al parecer, las ocupaciones modernas a las que se desplazan mujeres son prontamente redefinidas como "femeninas", por lo que aun cuando su ejecución signifique el uso de tecnologías complejas, los ingresos percibidos son inferiores a los de los hombres en las mismas ramas. Por lo tanto, es preciso investigar a fondo los cambios derivados de la incorporación de nuevas tecnologías en los procesos de producción y los movimientos de mayor o menor segregación de las ocupaciones que esta incorporación ha producido.

En los establecimientos financieros, la banca y los seguros, la modernización ha sido creciente en los últimos años. En 13 áreas urbanas de la región la participación femenina en esta rama alcanza magnitudes que fluctúan entre el $28 \%$ del total de ocupados (en Guatemala) y el $40 \%$ (en Venezuela); estas magnitudes han estado aumentando a partir de los años

\footnotetext{
${ }^{7}$ Las magnitudes para las áreas urbanas en 1990 son las siguientes: Argentina 38\%; Bolivia 29\%; Brasil 35\%; Colombia 36\%; Costa Rica 20\%; Chile 32\%; Guatemala 27\%; Honduras 35\%; Panamá $36 \%$; Paraguay $30 \%$; Uruguay $36 \%$ y Venezuela $40 \%$.
}

sesenta. ${ }^{7}$ En Brasil, un estudio que analiza los cambios tecnológicos y sus efectos en la división del trabajo por género muestra distintos mecanismos por los cuales no se reconoce la calificación femenina en el sector de la microelectrónica. Esos mecanismos son: el pago de una remuneración a las mujeres muy por debajo de su nivel de escolaridad; el no reconocimiento de las competencias adquiridas por las obreras en su socialización y en el ámbito doméstico; la desvalorización de la mayor disciplina y sumisión de las mujeres y, finalmente, el desconocimiento de la experiencia adquirida en empleos anteriores (Hirata y Humphrey, 1986, citado en Rangel de Paiva Abreu, 1993).

Una investigación en Chile muestra que la ocupación femenina ha aumentado considerablemente en el sector financiero. En 1990 la proporción de mujeres en ese sector (33\%) era superior al promedio de todos los sectores (31\%); sin embargo, los hombres monopolizaban los puestos gerenciales y directivos en una proporción mayor que en el conjunto de la economía (Hola y Todaro, 1992).

Un estudio realizado en Brasil en la industria gráfica muestra que la fuerza de trabajo ligada a las nuevas tecnologías es más joven e instruida que el conjunto de los empleados del sector; sin embargo, también en éste hay una nítida diferencia por sexos. Se observa que el nivel de ingreso para operadores de scanner (con menor instrucción y mayoría masculina), es de 14.1 salarios mínimos; para operadores de fotocomposición (con mayor escolaridad y un componente importante de mujeres) de 5.22 salarios mínimos, y para digitadores (con mayor nivel de instrucción y gran presencia femenina) de 4.7 salarios mínimos (Rangel de Paiva Abreu, 1993).

\section{Precarización del trabajo femenino}

Durante la crisis de comienzo de los años ochenta el crecimiento del sector informal constituyó la principal variable de ajuste del mercado laboral latinoamericano. El aumento del desempleo y de la informalidad fue acompañado con fuertes descensos de los ingresos laborales y una rápida precarización del empleo; se incrementó el empleo temporario y de tiempo parcial, y al mismo tiempo bajó la calidad del mismo. En 1989 más del 50\% de la ocupación no agrícola correspondía a microempresas o actividades informales - la cifra era de $38 \%$ en 1980 - a lo que habría que agregar el empleo precario (García, 1993).

Una de las tendencias ya señaladas para la región es al aumento del empleo no asalariado. La cri- 
sis y el nuevo patrón de reconversión productiva han provocado un aumento de ocupaciones - con altos componentes femeninos- que se pueden definir como precarias en términos de su discontinuidad en el tiempo, la falta de regulación laboral (ausencia de contratos); los salarios (no se respeta el salario mínimo), los horarios, la seguridad social y la higiene. Entre ellas cabe señalar viejas ocupaciones precarias, como el trabajo doméstico, y nuevas modalidades del trabajo a domicilio, por cuenta propia y en microempresas, que en algunos casos asume además el carácter de clandestino. Vemos así cómo la crisis, que hizo que las empresas medianas y grandes se recompusieran, reduciendo el número de ocupados; cómo la reestructuración, que llevó a reemplazar a los trabajadores permanentes por subcontratos con pequeñas empresas, y las diversas estrategias de supervivencia de los sectores más afectados por la crisis, convergieron hacia el desarrollo de las pequeñas unidades productivas. Ante la creciente heterogeneidad de las unidades productivas, su mayor o menor precariedad debe investigarse más a fondo. Sin embargo, en América Latina se aprecia una desregulación del trabajo y una pérdida de las conquistas laborales de los trabajadores.

En la medición de la participación femenina en el sector informal y precario se dan de manera mucho más aguda los problemas generales con que se tropieza al intentar medir el trabajo femenino. Muchas de las actividades realizadas por mujeres que podrían agruparse dentro de este sector no son registradas, ya que se consideran parte del trabajo doméstico que ellas ejecutan. Sin embargo, pese a ello se puede afirmar que las mujeres ocupadas más pobres se ubican en el sector informal urbano y que si se agrega a ellas las trabajadoras del hogar, la participación femenina en el sector supera el $70 \%$ en la mayoría de los casos. En algunos países de la región, según datos de las encuestas de hogares, las mujeres constituyen desde 8\% (Panamá) hasta 64\% (Cochabamba, Bolivia) del sector informal (Pollack, 1993).

A las dificultades propias de medir el trabajo informal se agrega la diversidad de definiciones y de indicadores para esa medición, lo que explica en parte las variaciones del tamaño estimado del sector informal. El carácter visible o no de este tipo de trabajo es una característica muy importante, ya que la actividad laboral de un sector importante de mujeres no es registrada. Un estudio sobre el sector informal realizado en Ciudad de Guatemala muestra que hay en él mayor presencia relativa de mujeres, de personas en edad avanzada (se plantea como un espacio para prolongar las trayectorias laborales), de migrantes, de indígenas y sobre todo de personas con niveles de instrucción bajos (Pérez Sáinz, 1992).

A continuación se examinará brevemente la situación de las trabajadoras en algunos tipos de ocupaciones nuevas y tradicionales con alto componente femenino, cuya principal característica es la precariedad. Las trabajadoras del hogar (sobre las que se tiene mayor información); las trabajadoras a domicilio y las trabajadoras por cuenta propia (sobre las cuales hay menos información y la que hay es más parcializada). Esta enumeración no es excluyente, puesto que en términos generales todas estas trabajadoras pueden incluirse en el sector informal. Sin embargo, no todas pertenecen a él, como es el caso de algunas trabajadoras por cuenta propia o a domicilio.

\section{a) Las trabajadoras del hogar}

Según las Naciones Unidas, si el trabajo doméstico se contabilizara aportaría hasta un $40 \%$ del producto nacional bruto de los países industrializados. A pesar de los grandes avances tecnológicos realizados para aliviar esa labor, en los países industrializados las mujeres trabajan en el hogar un promedio de 56 horas a la semana (Naciones Unidas, 1991).

En lo que toca al trabajo del hogar remunerado, o servicio doméstico, especialmente del que se efectúa con residencia en el hogar, se han señalado las siguientes características: unión de lugar de trabajo y vivienda, en el caso de las trabajadoras residentes; relaciones laborales que se aproximan a las de servidumbre y que mezclan lo laboral con lo afectivo y lo personal, y la elasticidad de la oferta en el caso de las trabajadoras no residentes (CEPAL, 1990). El servicio doméstico es un empleo de llegada, puesto que las posibilidades de ascenso sólo están dadas por un cambio de empleo y en contados casos por el paso de trabajadora residente a no residente. Por el carácter aislado de esta ocupación, las trabajadoras del hogar quedan fuera del circuito donde se presentan las oportunidades de empleo (Montero, 1992).

Hacia los años ochenta el trabajo doméstico era una de las ocupaciones que más absorbía mano de obra femenina. En 1990, en cambio, las mujeres ocupadas en el trabajo doméstico remunerado en las áreas urbanas de 13 países de la región representaban entre $7 \%$ (Venezuela) y 24\% (Paraguay) del total del empleo femenino. Entre los países que cuentan con informa- 
ción para los años 1980 y 1990 , el trabajo doméstico ha tendido a disminuir como ocupación de las mujeres en Brasil, Colombia, Costa Rica y Uruguay, en tanto que ha aumentado ligeramente en Argentina, Panamá y Venezuela. En este último país, pese a un aumento en relación con 1980 , la proporción de mujeres que se ocupan como trabajadoras del hogar es menor que en los demás países considerados. Esta tendencia a la disminución del trabajo doméstico remunerado en términos generales y como ocupación femenina ha sido señalada en algunos estudios, aun cuando se sostiene que el impacto de la crisis y los programas de ajuste han tendido a revertirla.

Pese a que puede haber un subregistro de la captación de trabajadoras del hogar, por ser éste un trabajo desvalorizado y de bajo prestigio, las cifras indican que esta ocupación es aún muy importante para las mujeres como puerta de entrada al mercado de trabajo.
Según algunos tabulados especiales de las encuestas de hogares para los años 1989 y 1990, la mayoría de las trabajadoras del hogar son jóvenes, solteras, tienen niveles bajos de educación y trabajan como residentes. Sin embargo, se observa una tendencia al desplazamiento hacia el trabajo no residente, situación que se produce con más frecuencia en los países con nivel de desarrollo mayor. Al mismo tiempo, hay notables diferencias entre países y según la modalidad de trabajo escogida: con o sin residencia en el hogar empleador. Las trabajadoras residentes son, en una inmensa mayoría, solteras, tienen menos de 30 años y un nivel de instrucción algo menor que las no residentes. Las trabajadoras no residentes en el hogar empleador presentan un nivel algo superior de instrucción, perciben ingresos medios más bajos, tienen más edad y en su mayoría están casadas o viven en unión consensual (cuadro 6).

Uno de los problemas más serios que enfrenta el sector de las trabajadoras del hogar es el aislamiento

CUADRO 6

América Latina (siete países): Características de las trabajadoras del hogar residentes y no residentes, $1990^{a}$

(Porcentajes)

\begin{tabular}{|c|c|c|c|c|c|c|c|}
\hline Características & Boliviab $^{b}$ & Brasil & Colombia & Chile & Guatemala & Uruguay & Venezuela \\
\hline \multicolumn{8}{|l|}{ Residentes } \\
\hline Solteras & 89.8 & $\ldots$ & 88.6 & 87.7 & 76.2 & 77.4 & 85.8 \\
\hline 10 a 29 años & 87.7 & 78.5 & 76.4 & 55.2 & 77.2 & 52.8 & 69.9 \\
\hline S/instrucción & 9.7 & 41.2 & 6.1 & $\ldots$ & $\ldots$ & 3.8 & 6.1 \\
\hline Primaria & 51.9 & 12.8 & 69.5 & $\ldots$ & $\ldots$ & 67.0 & 67.1 \\
\hline Ingreso medio ${ }^{c}$ & 47.4 & 38.0 & 91.1 & $\cdots$ & 48.7 & 84.1 & 44.7 \\
\hline \multicolumn{8}{|l|}{ No residentes } \\
\hline Solteras & 52.8 & $\ldots$ & 40.5 & 40.1 & 28.8 & 33.8 & 39.1 \\
\hline 10 a 29 años & 63.0 & 58.0 & 46.2 & 33.9 & 48.8 & 37.2 & 61.3 \\
\hline S/instrucción & 8.8 & 33.1 & 10.5 & $\ldots$ & 58.2 & 3.8 & 13.0 \\
\hline Primaria & 52.1 & 27.7 & 64.6 & $\ldots$ & 7.9 & 63.6 & 67.2 \\
\hline Ingreso medio ${ }^{c}$ & $\ldots$ & 35.7 & $\ldots$ & $\ldots$ & 27.4 & 29.5 & 22.1 \\
\hline
\end{tabular}

Fuente: Tabulados especiales de las encuestas de hogares de empleo y desempleo de 1989 y 1990 realizados por Rosa Bravo para el Segundo Encuentro de la Confederación de Trabajadoras del Hogar de América Latina y el Caribe.

a Población de áreas urbanas de 10 y más años.

b Población de áreas urbanas de 15 años y más.

c Ingreso medio de las trabajadoras del hogar residentes y no residentes como porcentaje del ingreso medio de los ocupados.

en que trabajan, lo que dificulta la organización y la lucha corporativa para mejorar sus condiciones laborales. Su situación se ve perjudicada, además, porque no están protegidas por la legislación laboral ordinaria, bajo el pretexto de que no tienen un lugar común de trabajo, no producen un bien tangible y son pagadas en parte con comida y vivienda. En aquellos países en que se ha legislado para otorgarles ocho horas de descanso (Perú, por ejemplo), la legislación ha tenido un efecto indeseado, ya que las patronas lo han interpretado como licencia para exigir 16 horas de trabajo (Chaney y Castro, 1993). Sin embargo, se aprecia un cambio importante, puesto que las trabajadoras del hogar han logrado organizarse y han constituido una confederación regional que agrupa a 11 países latinoamericanos. (Confederación de Trabajadoras del Hogar de América Latina y el Caribe). Este enorme esfuerzo organizativo, si bien no abarca al total de las 
ocupadas en el sector, indica una importante toma de conciencia como trabajadoras.

\section{b) Las trabajadoras a domicilio}

La existencia del trabajo a domicilio emana de la búsqueda de procesos de producción más baratos, sobre todo para aquellas tareas con uso intensivo de mano de obra. El trabajo domiciliario contribuye a aumentar la flexibilidad de la oferta de mano de obra frente a una demanda sin reglamentación de horarios ni de duración del período trabajado (Benería y Roldán, 1992). Este trabajo no requiere el uso de herramientas o máquinas, pues más bien hace uso intensivo de mano de obra; exige muy poca inversión y puede efectuarse con facilidad en el hogar. En general, representa un tramo o una parcela del proceso de producción, en tareas sencillas, repetitivas y monótonas. El aumento de la flexibilidad geográfica por la adopción de nuevas tecnologías plantea un potencial reorganizativo que puede incidir considerablemente en el aumento de la participación laboral femenina.

El trabajo domiciliario responde a una estrategia moderna de producción flexible que apunta a una mayor acumulación para el capital y a una estrategia de generación de ingresos para los trabajadores (Benería y Roldán, 1992). Es una alternativa posible al trabajo cumplido en forma regular para personas con responsabilidades familiares (el caso mayoritario de las mujeres que trabajan en esta modalidad), con incapacidad física o simplemente con necesidad de independencia. Cuando el índice de desempleo aumenta, constituye también un medio de obtener ingresos para quienes no pueden encontrar un trabajo fijo. Las mujeres que trabajan a domicilio representan la mano de obra más barata, que en una coyuntura de crisis y ajuste permite resolver el dilema de elevar los ingresos familiares junto con intensificar el trabajo doméstico. Las actividades en las que se concentra el trabajo domiciliario son tradicionales: la confección, la industria textil, la del cuero, el calzado, el tabaco y otras.

No existen suficientes estudios de cobertura regional que permitan mostrar la evolución de este segmento de trabajadoras; sin embargo, está claro que sus condiciones laborales, como las de las trabajadoras informales y las trabajadoras del hogar, no están sujetas a regulación alguna, o si lo están, esta regulación no se cumple. Existe una dependencia extrema de las trabajadoras domiciliarias que son subcontratadas, en la medida en que las negociacio- nes para la fijación de precios y la continuidad de las entregas se realicen a través de terceros, que actúan como intermediarios entre ellas y la empresa. Sin embargo, por ser ésta una ocupación en la cual las decisiones técnicas y de producción corresponden al empleador, podría ser considerada un trabajo asalariado y como tal estar sujeta a las regulaciones pertinentes, con la diferencia de que se realiza en un lugar externo a la empresa, en el hogar del trabajador, que no tiene estabilidad en el tiempo y que se paga a destajo.

Una de las conclusiones generales a las que se llega a través de un análisis comparado del trabajo a domicilio en países desarrollados y en países en desarrollo es que en las distintas legislaciones nacionales esta actividad aparece como "regulada" por un amplio cuerpo normativo. El problema fundamental sería entonces la escasa aplicación de esa normativa. Así, "...el trabajo a domicilio aparece como un fenómeno disperso, aislado y falto de control; a decir verdad, si hay un apelativo que pueda definir globalmente este fenómeno, es sin duda el de "precario"" (Vega, 1992, p. 19).

\section{c) Las trabajadoras por cuenta propia}

El sector de trabajadoras por cuenta propia es una categoría que presenta gran diversidad en censos y encuestas de hogares, por cuanto puede incluir desde la profesional independiente (médica o dentista) hasta la vendedora ambulante, cuyo trabajo puede ser incluso semiclandestino. Lo que distingue al empleo por cuenta propia del empleo asalariado es la forma de remuneración, que no proviene de un empleador sino que es producto de la propia gestión de una empresa o del ejercicio independiente de una profesión $\mathrm{u}$ oficio. Indudablemente, la precariedad de esta categoría está dada - para las mujeres que no son profesionales independientes - por la ausencia de seguridad social, vacaciones, licencias por maternidad o por enfermedad y otros beneficios a los que acceden las asalariadas. La información extraída de las encuestas de hogares muestra que la categoría ocupacional de trabajadores por cuenta propia creció entre los años 1980 y 1990. Las magnitudes de hombres y mujeres que trabajan por cuenta propia son bastante similares, salvo en Bolivia, donde más de la mitad de las mujeres ocupadas lo está bajo esa modalidad. ${ }^{8}$

\footnotetext{
${ }^{8}$ Según los datos de las encuestas del año 1990 los porcentajes de mujeres urbanas que trabajan por cuenta propia o son familiares no remunerados son los siguientes: Argentina 26\%; Bolivia 55\%; Brasil
} 
En los años ochenta tanto hombres como mujeres aumentaron su participación en esta modalidad laboral en todos los países de la región. Sin embargo, se observa que las mujeres se desempeñan como trabajadoras por cuenta propia en mayor proporción en países con fuertes contingentes indígenas: Bolivia, Guatemala, Honduras y Paraguay. Otra categoría ocupacional numéricamente muy pequeña, pero que también percibe muy bajos ingresos, es la de las trabajadoras familiares (con o sin remuneración). Por ello, para evaluar cabalmente la precariedad del trabajo por cuenta propia del sector informal debe hacerse un análisis más detallado del que permiten las encuestas de hogares, que incluya horas "trabajadas, ingresos percibidos y trayectorias laborales.

Un estudio realizado en Buenos Aires muestra que los trabajadores por cuenta propia han aumentado en las últimas décadas. Al compararlos con los trabajadores asalariados, se observa que los primeros tienen mayor edad, especialmente en el caso de las mujeres, las que también han migrado más y presen$\tan$ mayores grados de informalidad en el empleo (Gallart, Moreno y Cerrutti, 1990). A la misma conclusión se llega respecto del conjunto de las trabajadoras informales en Chile, las que tienen menor nivel de instrucción y mayor edad que el resto de los trabajadores y también que los hombres ocupados en el sector informal urbano.

Se ha buscado favorecer a los trabajadores por cuenta propia con diversas medidas, como sistemas crediticios especiales, capacitación enfocada al desarrollo de capacidades empresariales, apoyo a la gestión de las pequeñas empresas y otras. Sin embargo, habrá que contemplar también medidas especiales para las mujeres trabajadoras por cuenta propia, las que combinan tanto habilidades como dificultades específicas derivadas del sistema de género imperante en la región.

\section{IV}

\section{Comentarios finales}

\section{Síntesis}

América Latina ha superado parcialmente la etapa de ajuste de corto plazo tras la crisis de la deuda externa de comienzos de los años ochenta; se encuentra ahora en una etapa de reestructuración marcada por la apertura a los mercados externos, e intenta integrarse al comercio internacional en condiciones de competitividad. Este proceso ha traído un gran dinamismo al mercado de trabajo, expresado en cambios en el papel del Estado, en la regulación de las relaciones laborales y, en general, en las políticas de empleo, salarios y formación profesional.

Estos cambios, que han incluido una reorganización de los procesos productivos con incorporación de nuevas tecnologías, han modificado la composición del mercado de trabajo, y sus efectos en la participación laboral femenina se han hecho sentir fuertemente. Entre ellos el más notorio ha sido el llamado "feminización de la fuerza de trabajo" o "revolución silenciosa". Este fenómeno viene regis-

24\%; Colombia 24\%; Costa Rica 18\%; Chile 22\%; Guatemala $37 \%$; Honduras $39 \%$; México $21 \%$; Panamá $14 \%$; Paraguay $30 \%$; Uruguay $21 \%$ y Venezuela $20 \%$. trándose desde los años sesenta y aun cuando su ritmo se haya desacelerado en los últimos años, sigue en aumento.

No obstante que el incremento de la participación femenina tiende a acercarla a la participación masculina, las pautas por género son diferentes y la brecha sigue siendo amplia. Desde el lado de la oferta de mano de obra hay variaciones según la edad y el estado civil- las que tienden a disminuir-y la instrucción de las mujeres. Por el lado de la demanda de mano de obra, se emplea a las mujeres en un número menor de ocupaciones, se las remunera muy por debajo de los hombres y la participación femenina es mayoritaria en el sector informal y más precario. No cabe duda de que en el decenio de 1980 ha habido importantes cambios en la situación de las mujeres trabajadoras, los que obligan a modificar percepciones sobre el trabajo femenino que se sostienen hasta ahora. En estas tendencias se observan continuidades, y también rupturas que tienden a tornar obsoletas muchas de las afirmaciones sostenidas hasta ahora.

La información proveniente de las encuestas de hogares para las áreas urbanas de 13 países latinoamericanos muestra -al igual que numerosos estu- 
dios de la región- la creciente participación femenina en el mercado de trabajo, especialmente de las mujeres en edades intermedias ( 25 a 45 años) y casadas. Junto a esta feminización de la fuerza de trabajo se observa una terciarización de la población activa (en el sector servicios se abrieron nuevas oportunidades de empleo para las mujeres) y crecimiento de las actividades económicas en pequeña escala. Este aumento de la participación económica de las mujeres en la región apunta a la ambivalencia del cambio, ya que a la vez se mantiene un mercado de trabajo altamente segmentado y se da una creciente precarización del trabajo femenino, expresada en niveles de ingresos notoriamente inferiores a los masculinos, en tasas de desempleo generalmente mayores que las masculinas y en el aumento del trabajo femenino por cuenta propia y en el sector informal.

\section{Sugerencias metodológicas}

Cabe hacer aquí algunos comentarios metodológicos en relación con el análisis de la situación laboral. Ante todo, es importante analizar las relaciones de género en el mercado de trabajo. No hacerlo tiende a oscurecer el análisis del sector laboral, puesto que tendencias contrapuestas en hombres y mujeres se anulan si se las considera en su conjunto.

Es importante también evaluar los cambios con cierta continuidad, dada la velocidad con que evoluciona el sector laboral, especialmente en variables sensibles como tasas de actividad, ocupación y desocupación, ingresos medios y otros; afirmaciones que eran válidas al inicio de la crisis no lo son para las fases de recuperación económica.

$\mathrm{El}$ análisis indica que para comprender a fondo los procesos de cambio en los países es preciso conocer el contexto en que se produjo la crisis y se aplicaron las políticas de ajuste, pues éste cobra enorme importancia al momento de entender las diferentes reacciones del mercado de trabajo y de los actores sociales, hombres y mujeres.

Tales procesos refuerzan la idea de evaluar continuamente el efecto de los cambios externos y de las intervenciones sociales. Los efectos no deseados de la legislación sobre el descanso de las trabajadoras del hogar (ejemplo que se dio más atrás), o lo que ocurrió cuando se legisló sobre la necesidad de guarderías infantiles en las empresas, alertan sobre la necesidad de evaluación continua, no sólo para verificar la aplicación de las medidas legislativas, sino también para evitar que se desvirtúe el sentido de la normativa.

Por último, del examen de las características que asume el empleo femenino se puede concluir que la creciente participación laboral de las mujeres no puede considerarse como la única dimensión clave; en la actualidad, otras facetas adquieren importancia al evaluar la situación laboral femenina, tales como las condiciones de trabajo, la ampliación de las opciones laborales y la ruptura de la segmentación ocupacional.

\section{Significado de los cambios}

Un desafío que queda pendiente es el de dilucidar la relación recíproca entre las dimensiones de la participación económica femenina y los efectos que pueden manifestarse en otros ámbitos, como el familiar, social, político y cultural. Se sabe que la evolución de estas dimensiones tiene un ritmo desigual, pero también se sabe que su interrelación es tal que al producirse cambios en una dimensión las otras se verán necesariamente afectadas; la magnitud y la dirección de estos cambios es lo que debe analizarse. Por esta misma línea se plantea una interrogante: la participación laboral femenina, que es un requisito mínimo para la autonomía de las mujeres, ¿se traduce en autonomía en otros planos, o en un aumento de sus responsabilidades y una sobrecarga de trabajo?

En las nuevas propuestas de desarrollo, especialmente la de transformación productiva con equidad de la CEPAL, la calificación de los recursos humanos es uno de los pilares de sustentación. No cabe duda de que la mano de obra femenina altamente calificada es un recurso mal utilizado en el mercado de trabajo: no se la remunera por el nivel de educación alcanzado y se la segrega en un número limitado de ocupaciones. Sin embargo, la calificación adquirida por las mujeres podría ser aprovechada en el mercado de trabajo si se ampliaran las oportunidades laborales para ellas, rompiendo la rígida segmentación de ocupaciones tanto vertical como horizontal. El cambio en la organización del sistema productivo ofrece a las mujeres oportunidades que deben aprovecharse. El que esas potencialidades refuercen o rompan la segmentación ocupacional, por ejemplo, dependerá de la capacidad de negociación que logren las mujeres trabajadoras. Desde la perspectiva del mercado de trabajo, la mayor flexibilidad de la mano de obra femenina con niveles de instrucción elevados 
podría transformarse en altamente atractiva en el nuevo patrón de desarrollo.

Desde el punto de vista de las biografías sociales, la situación laboral femenina muestra mayor complejidad y heterogeneidad que la de su contraparte masculina. En el futuro tendrá mayores potencialidades y posibilidades para recorrer trayectorias laborales distintas de las de su propio grupo etario y de distintas generaciones, a medida que su flexibilidad como recurso humano sea mayor.

La existencia de un tercio de mano de obra regional femenina tiene un significado distinto en el imaginario cultural de la región. En primer lugar, es una magnitud que no se puede desconocer ni negar. En segundo lugar, tiene un efecto de demostración mayor sobre el conjunto de la sociedad, ya que hoy la existencia del trabajo remunerado como una opción para las mujeres es indiscutible. Queda por dilucidar si en el futuro se cuestionará en el nuevo escenario la "ambigüedad" que impera en el reconocimiento del derecho al trabajo de las mujeres, no en la legislación, sino en las prácticas sociales (Aguirre, 1990); esa ambigüedad se traduce en falta de servicios de apoyo a nivel social, falta de respaldo a nivel familiar y sentimiento de culpa de las mujeres por no cumplir con sus obligaciones "naturales". La consecuencia de incorporar en el imaginario social el hecho de que las mujeres trabajan fuera de sus casas cuando tienen hijos pequeños debería manifestarse en más servicios de apoyo, especialmente para el cuidado de los hijos en edad preescolar (con salas cunas y guarderías infantiles) y en edad escolar (con la ampliación de la estadía en los colegios para hacerla coincidir con la jornada laboral).

En cuanto a la relación entre trabajo y familia, los cambios en el empleo femenino sin duda tienen efectos en la familia. La capacidad de negociación de la mujer al interior de la familia cuando cuenta con un ingreso es por supuesto mayor. Sin embargo, se sabe que la distribución del trabajo por género dentro del hogar permanece bastante inalterada. $\mathrm{Si}-$ como muestran los datos - el mayor aumento de la participación femenina se observa entre las mujeres casadas y con hijos, y a la vez está disminuyendo la proporción de trabajadoras del hogar, la consecuencia en términos de sobrecarga de trabajo para las mujeres es indudable. Esta comprobación refuerza la necesidad de políticas que apunten a intervenciones claves en el cuidado de lo niños.

Desde la perspectiva del mercado laboral, por otro lado, queda un amplio campo de acción que incluye la regulación de horarios y remuneraciones del trabajo domiciliario, por cuenta propia o subcontratado, y la valoración necesaria de la mano de obra femenina por los empleadores. La sociedad tiene aún como tarea pendiente el reconocimiento del trabajo doméstico y especialmente de crianza que ejecutan las mujeres como trabajo socialmente necesario y factible de ser realizado por ambos sexos.

\section{Bibliografia}

Abramo, Lais (1993): Reconversión productiva, cambio tecnológico y empleo femenino en América Latina, documento presentado al Seminario latinoamericano sobre las repercusiones de la reconversión productiva y el cambio tecnológico sobre el empleo y las condiciones de trabajo de la mujer en América Latina, Santiago de Chile, Organización Internacional del Trabajo (OIT)/ Servicio Nacional de la Mujer (SERNAM), 8 al 12 de marzo.

Aguirre, Rosario (1990): Los efectos de la crisis sobre la mujer en el Uruguay, Documentos de trabajo, $\mathrm{N}^{\circ} 60$, Montevideo, Centro Interdisciplinario de Estudios sobre el Desarrollo (CIEDUR).

Aranda, Ximena (1991): Tejenderas de Putaendo. Para no mirar la cerca en redondo, Proyecto La Edición Pepa Foncea/Instituto de Cooperación Iberoamericana (ICl), Santiago de Chile.

Barbezat, Debra (1993): Occupational Segmentation by Sex in the World, Women/WP-13, Ginebra, OIT/IDP.

Benería, Lourdes (1992): The Mexican debt crisis: Restructuring the economy and the household, L. Benería y S. Feldman (eds.), Unequal Burden: Economic Crisis, Persistent Poverty, and Women's Work, Oxford, Westview Press.

Benería, Lourdes y Martha Roldán (1992): Las encrucijadas de clase y género. Trabajo a domicilio, subcontratación y dinámica de la unidad doméstica en la Ciudad de México, México, D.F.,Colegio de México/Fondo de Cultura Económica/Economía Latinoamericana.

Bonilla, Elssy (1992): La mujer colombiana en la universidad y en el mundo del trabajo, Boletín, $\mathrm{N}^{\circ} 29$, Proyecto principal de educación en América Latina, Organización de las Naciones Unidas para la Educación, la Ciencia y la Cultura (UNESCO), Oficina Regional de Educación de la UNESCO para América Latina y el Caribe (OREALC).

CELADE (Centro Latinoamericano de Demografía) (1989): Boletín demográfico, año XXII, $\mathrm{N}^{\circ} 44$, LC/DEM/G.80, Santiago de Chile.

(1991): Boletín demográfico, año XXIV, No 47, LC/DEM/ G. 97, Santiago de Chile.

(1993): Boletín demográfico, año XXVI, No 52, LC/DEM/ G. 135, Santiago de Chile.

CEPAL (1990): Los grandes cambios y la crisis. Impacto sobre la mujer en América Latina y el Caribe, LC/G. 1592-P, Santiago de Chile. Publicación de las Naciones Unidas, $\mathrm{N}^{\circ}$ de venta $\mathrm{S}$. 90.II.G.13.

(1993): Panorama social de América Latina, LC/G.1768, Santiago de Chile.

(1994): La cumbre social: una visión desde América Lati- 
na y el Caribe (Nota de la Secretaría), LC/G.1802(SES.25/5), Santiago de Chile.

Chaney, Elsa y Mary García Castro (eds.) (1993): Muchacha, cachifa, empleada, empregadinha, sirvienta y... más nada, Venezuela, Editorial Nueva Sociedad.

Darcy de Oliveira, Rosyska (1989): Femme et travail-sens, nonsens et ambigüité, trabajo presentado en el coloquio L'accés des femmes au travail salarié comme source de changement social et ses effets sur la socialisation des femmes et des autres membres de la collectivité, Ankara, Turquía, UNESCO.

Filgueira, Nea (1992): Mujeres uruguayas: un futuro incierto, Serie Lila, $\mathrm{N}^{\circ} 28$, Montevideo, Grupo de Estudios sobre la Condición de la Mujer en el Uruguay (GRECMU).

Gallart, Antonia, Martín Moreno y Marcela Cerrutti (1990): Estrategias laborales de los trabajadores por cuenta propia del Area Metropolitana de Buenos Aires, P. Galin y M. Novick (comps.), La precarización del empleo en la Argentina, Buenos Aires, Centro Internacional de Agricultura Tropical (CIAT)/Consejo Latinoamericano de Ciencias Sociales (CLACSo)/ Bibliotecas Universitarias/ Centro Editor de América Latina (CEAL).

García, Brígida y Orlandina de Oliveira (1993): Trabajo femenino y vida familiar en México, México D.F., Colegio de México.

García, Norberto (1993): Reestructuración económica y mercados de trabajo, Instituto Internacional de Estudios Laborales (IIEL), Restructuración y regulación institucional del mercado de trabajo en América Latina, Serie de Investigación, $\mathrm{N}^{\circ}$ 98, Ginebra.

Garrido, Luis (1992): Las dos biografias de la mujer en España, Madrid, Ministerio de Asuntos Sociales, Instituto de la Mujer (IM).

Geldstein, Rosa (1992): Aumentan los hogares sostenidos por las mujeres, Boletín del SIDEMA, $\mathrm{N}^{\circ} 5$, Argentina, Servicio de Información Documental y Estadística sobre la Mujer en la Argentina (SIDEMA), diciembre.

Gindling, T. H. (1992): La mujer y la crisis económica en Costa Rica, Ciencias económicas, vol. XII, N 2 , San José, Costa Rica, Editorial de la Universidad de Costa Rica.

González, Pablo (1992): El diferencial de ingresos entre hombres y mujeres: teoría, evidencia e implicaciones de política, Colección Estudios CIEPLAN, $\mathrm{N}^{\circ} 34$, Santiago de Chile, Corporación de Investigaciones Económicas para Latinoamérica (CIEPLAN).

Guzmán, Virginia y Patricia Portocarrero (1992): Construyendo diferencias, Lima, Flora Tristán Ediciones.

Hola, Eugenia y Rosalba Todaro (1992): Los mecanismos del po- der: hombres y mujeres en la empresa moderna, Santiago de Chile, Centro de Estudios de la Mujer (CEM).

Montero, Cecilia (1992): Los problemas de integración social: el caso de los empleos femeninos y masculinos de fácil acceso, Proposiciones: Género, mujer y sociedad, $\mathbf{N}^{\circ} 21$, Santiago de Chile, Sur Ediciones.

Montoya, Silvia (1993): Implicancias distributivas del trabajo femenino, Estudios, año XVI, $N^{\circ} 67$, Córdoba, Argentina, Instituto de Estudios Económicos sobre la Realidad Argentina y Latinoamericana (IEERAL).

Mujer/Fempress (1994): No 148/149, Santiago de Chile, ILET, febrero-marzo.

Naciones Unidas (1989): Estudio mundial sobre el papel de la mujer en el desarrollo 1989, ST/CSDHA/6, Nueva York. Publicación de las Naciones Unidas, $\mathrm{N}^{\circ}$ de venta S.89.IV.2.

(1991): La mujer. Retos hasta el año 2000, Nueva York. Publicación de las Naciones Unidas, $\mathbf{N}^{\circ}$ de venta S.91.I.21.

(1992): Situación de la mujer en el mundo. Tendencias y estadísticas 1970-1990, serie K, $\mathrm{N}^{\circ}$ 8, ST/ESA/STAT/SER.K/ 8 , Nueva York.

Pérez Sáinz, Juan Pablo (1992): Empleo informal en la Ciudad de Guatemala, Mujer y sector informal, Ciudad de Guatemala, Facultad Latinoamenricana de Ciencias Sociales (FLACSO)/ Oficina Nacional de la Mujer (ONAM)/Fondo de las Naciones Unidas para la Infancia (UNICEF).

Pollack, Molly (cons.) (1993): ¿Feminización del sector informal en América Latina y el Caribe?, Serie mujer y desarrollo, $\mathrm{N}^{\circ}$ 11, LC/L.731, Santiago de Chile, CEPAL.

Psacharopoulos, George y Zafiris Tzannatos (1992): Women's Employment and Pay in Latin America. Overview and Methodology, Regional and sectoral studies, Washington, D.C., Banco Mundial.

Rangel de Paiva Abreu, Alice (1993): Mudança tecnológica e gênero no Brasil, Novos Estudos, No 35, São Paulo, Brasil, Centro Brasileño de Análisis y Planeamiento.

Rendón, Teresa (cons.) (1993): El trabajo femenino en México en el marco de la transformación productiva con equidad, LC/MEX/ R.407, México, D.F., Sede Subregional de la CEPAL en México.

Rico, Nieves (cons.) (1994): Formación y desarrollo de los recursos humanos femeninos: un desafío para la equidad, LC/ L.829, Santiago de Chile, CEPAL.

SERNAM (Servicio Nacional de la Mujer) (1993): Situación de las mujeres en el mercado de trabajo en 1992. Informe de coyuntura, Santiago de Chile, Programa de Economía del Trabajo (PET)/ SERNAM, mayo.

Vega, Luz (1992): El trabajo a domicilio: ¿Hacia una nueva regulación?, Revista internacional del trabajo, vol. III, $\mathrm{N}^{\circ} 1, \mathrm{Gi}-$ nebra, OIT. 